\title{
Control principles of micro-source inverters used in microgrid
}

\author{
Wenming Guo ${ }^{*}$ and Longhua Mu
}

\begin{abstract}
Since micro-sources are mostly interfaced to microgrid by power inverters, this paper gives an insight of the control methods of the micro-source inverters by reviewing some recent documents. Firstly, the basic principles of different inverter control methods are illustrated by analyzing the electrical circuits and control loops. Then, the main problems and some typical improved schemes of the $\omega \mathrm{U}$-droop grid-supporting inverter are presented. In results and discussion part, the comparison of different kinds of inverters is presented and some notable research points is discussed. It is concluded that the most promising control method should be the $\omega U$-droop control, and it is meaningful to study the performance improvement methods under realistic operation conditions in the future work.
\end{abstract}

Keywords: Mirogrid, Micro-source inverter, Droop control, Control principle

\section{Introduction}

Recently, with the increased concern on environment and intensified global energy crisis, the traditional centralized power supply has shown many disadvantages.Meanwhile, the high-efficiency, less-polluting distributed generation (DG) has received increasing attentions $[1,2]$. Microgrids [3-5], which comprise micro-sources, energy storage devices, loads, and control and protection system, are the most effective carrier of DGs. When a microgrid is connects to the utility grid, it behaves like a controlled load or generator, which removes the power quality and safety problems caused by DGs' direct connection. Microgrids can also operate in islanded mode, thus increase system reliability and availability of the power supply.

Proper control is a precondition for microgrids' stable and efficient operation. The detailed control requirements come from different aspects, such as voltage and frequency regulation, power flow optimization etc. Since these requirements are of different importance and time scale, a three-level microgrid control structure is proposed in [6]. As the foundation of microgrid control system, the primary control is aimed at maintaining the basic operation of the microgrid without communication, which has become a hot research topic recently. Since most microsources utilize inverters to convert electrical energy, the primary control is essentially the management of power

\footnotetext{
* Correspondence: gwmsch@163.com

Department of Electrical Engineering, Tongji University, Shanghai, China
}

inverters. Micro-source inverters are required to work in a coordinated manner based only on local measurements and the control strategies decide the roles of each microsource. According to the principle of master-slave control, the micro-source inverters can be divided into gridfeeding, grid-forming, and PQ-droop grid-supporting inverters. From the perspective of peer control, the $\omega \mathrm{U}$ droop grid-supporting invertershelp to realize microgrids' plug and play function. Although being widely discussed in the technical literatures, it still lacks a sufficient practical control method andexisting control technologies need to be further studied and improved. This paper describes the control principles of several typical microsource inverters and compares their characteristics so as to provide a fundamental understanding of microgrids' primary control.

\section{Method}

\section{Grid-feeding inverter}

The control objective of grid-feeding (GFD) [11] inverter is to track the specified power references. Figure 1 illustrates the control block diagram of the most common current controlled GFD inverter. For dispatchable microsources, such as micro-turbine and fuel-cells, the inverter power references can be set directly according to practical requirements. For non-dispatchable micro-sources, such as photovoltaic cells, the active power reference is usually decided by the voltage controller of the inverter's DC bus. 


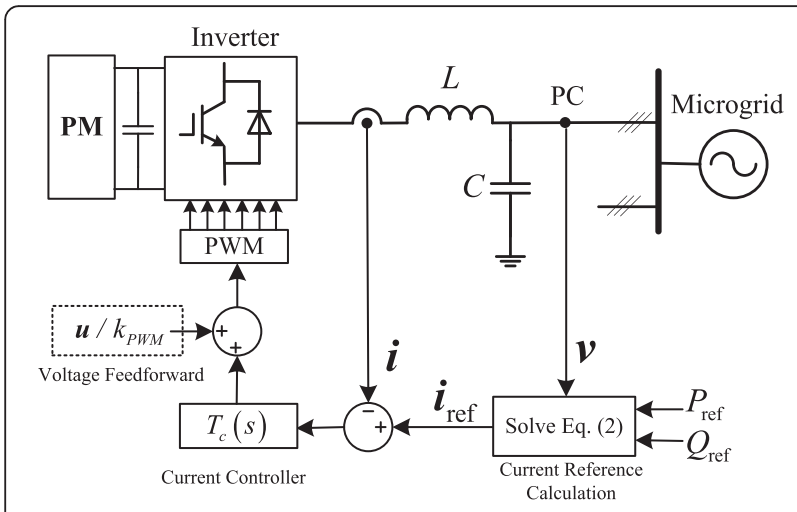

Fig. 1 Control block diagram of grid-feeding inverter

In addition, this type of sources can also export reactive power without affecting maximum power point tracking.

The GFD inverter's power referencetrackingis realized by adjusting the output currents. The control system calculates the output current references based on the relationships among the inverter's output power, output current and the voltage at the point of connection (PC). The three-phase voltages at the PC are represented by vector $\boldsymbol{v}$, and the inverter's output currents are represented by vector $\boldsymbol{i}$ as

$$
\begin{aligned}
& \boldsymbol{v}=\left[\begin{array}{lll}
\boldsymbol{v}_{a} & \boldsymbol{v}_{b} & \boldsymbol{v}_{c}
\end{array}\right]^{T} \\
& \boldsymbol{i}=\left[\begin{array}{lll}
\boldsymbol{i}_{a} & \boldsymbol{i}_{b} & \boldsymbol{i}_{c}
\end{array}\right]^{T}
\end{aligned}
$$

Neglecting the power consumed on the filter inductor, the output power of GFD inverter is calculated according to instantaneous power theory [7] as:

$$
\left\{\begin{array}{l}
P=\boldsymbol{v} \cdot \boldsymbol{i} \\
Q=-|\boldsymbol{v} \times \boldsymbol{i}|
\end{array}\right.
$$

If the current controller in Fig. 1 is properly designed, the output currents of the GFDinverter will follow their references. Thus the current reference vector, $\boldsymbol{i}_{\text {ref }}$, can be obtained by solving the following equation:

$$
\left\{\begin{array}{l}
P_{r e f}=\boldsymbol{v} \cdot \boldsymbol{i}_{\text {ref }} \\
Q_{\text {ref }}=-\left|\boldsymbol{v} \times \boldsymbol{i}_{\text {ref }}\right|
\end{array}\right.
$$

The output currents of the GFD inverter are the same as the currents flownthrough the filter inductor. In natural reference frame, there exists the following relation:

$$
s L \boldsymbol{i}=\boldsymbol{u}_{i n v} \quad-\boldsymbol{u}
$$

The voltages at the PC, $\boldsymbol{u}$, are measured using voltage transducers, the output voltages of the inverter, $\boldsymbol{u}_{\text {inv }}$, can then be adjusted based on $\boldsymbol{u}$ (see the voltage feedforward in Fig. 1) to control the voltage drop on the filter inductor. This implies that the filter inductor's currents can be controlled indirectly. If the potential at the middle point of the inverter's DC bus equal zero and ignore the delay of PWM process, the inverter is equivalent to a proportional element with gain $k_{\mathrm{PWM}}$. Thus, the closed-loop transfer function of the inverter's current control can be written as:

$$
G_{c}(s)=\frac{k_{p w m} T_{c}(s)}{s L+k_{p w m} T_{c}(s)}
$$

$T_{\mathrm{c}}(\mathrm{s})$ needs be designed in a way to ensure $G_{\mathrm{c}}(\mathrm{s})$ have sufficient bandwidth. Meanwhile, the gain and phase shift of $G_{\mathrm{c}}(\mathrm{s})$ around fundamental frequency should be close to $0 \mathrm{~dB}$ and 0 degree respectively. Therefore, the output current of the GFD inverter can track their references quickly and accurately.

For three-phase balanced operation cases, the control system of the GFD inverter is usually designed in $d q$ reference frame, where the voltages and currents are DC signals. In this case, using PI controller can realize the output current tracking without steady-state error. In $d q$ reference frame, the Park transformation will result in coupling between the $d$ and $q$ axis inductor currentcomponents, as shown in Eq. (5). Therefore, the control system must comprise $d q$ decoupling modules. The detailed control block diagram in $d q$ reference frame is illustrated in Fig. 2.

$$
s L \boldsymbol{I}_{d q}=\boldsymbol{U}_{i n v, d q}-\boldsymbol{U}_{d q^{-}}\left[\begin{array}{cc}
0 & -\omega L \\
\omega L & 0
\end{array}\right] \boldsymbol{I}_{d q}
$$

For unbalanced operation cases, the GFD inverters need simultaneously controlthe positive and negative sequence currents $[8,9]$. Under such condition, using PR controller [10] in $\alpha \beta$ reference frame might be a better choice as a single PR controller can regulate both the positive and negative sequence currents, and the control effect is similar to that of using two PI controllers in double positive/negative $d q$ reference frames.

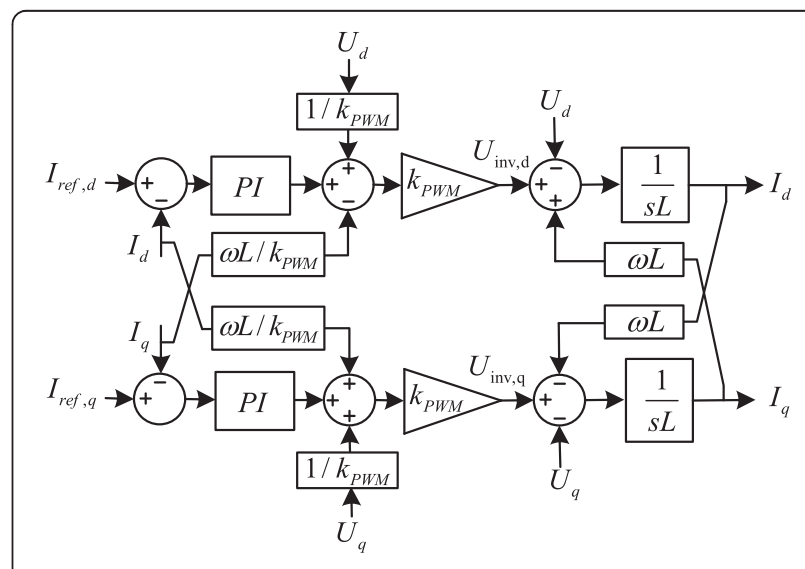

Fig. 2 Current control loop of GFD inverters in dq reference frame 


\section{Grid-forming inverter}

The control objective of the grid-forming (GFM) [11] inverters is to maintain stable voltage and frequency in a microgrid. GFM inverters are characterized by their low output impedance, and therefore they need a highly accurate synchronization system to operate in parallel with other GFM inverters [11]. GFM inverters usually equips with energy storage on their DC sides, therefore they can respond to the change of load in a short time. The control block diagram of a GFM inverter is shown in Fig. 3, including an inner inductor current loop, which is identical to that of the GFD inverter, and an outer capacitor voltage loop. GFM inverters achieve their control objective by regulating the filter capacitor's voltage, $\boldsymbol{u}$. In natural reference frame, there exists the following relation:

$$
s C \boldsymbol{u}=\boldsymbol{i}-\boldsymbol{i}_{o}
$$

where $\boldsymbol{i}$ and $\boldsymbol{i}_{\mathrm{o}}$ are the inductor and grid currents, respectively.

According to the above analysis, the GFM inverters can also precisely control their inductor current by a properly designed inner current loop. The impact of the grid current on capacitor voltage is removed by current feedforward and thus, $\boldsymbol{u}$ is fully controlled by adjusting $\boldsymbol{i}$.

As shown in Eq. (7), in the $d q$ reference frame, the $d$ and $q$ axis component of the filter capacitor voltage are also coupled. Similarly, it is necessary to introduce $d q$ decoupling modules in the voltage control loop as illustrated in Fig. 4.

$$
s C \boldsymbol{U}_{d q}=\boldsymbol{I}_{d q^{-}}-\boldsymbol{I}_{o, d q^{-}}\left[\begin{array}{cc}
0 & -\omega C \\
\omega C & 0
\end{array}\right] \boldsymbol{U}_{d q}
$$

\section{Grid-supporting inverter}

There exists an approximate linear droop relation between the P- $\omega$ and Q-U of traditional synchronous generators. By emulating this output characteristics, grid-supporting (GS) [11] inverters, aimed at sharing load proportional to their

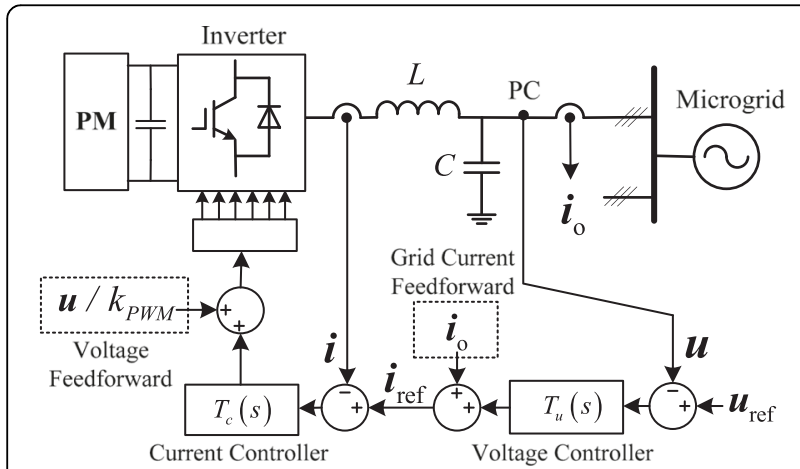

Fig. 3 Control block diagram of three-phase grid-forming inverter

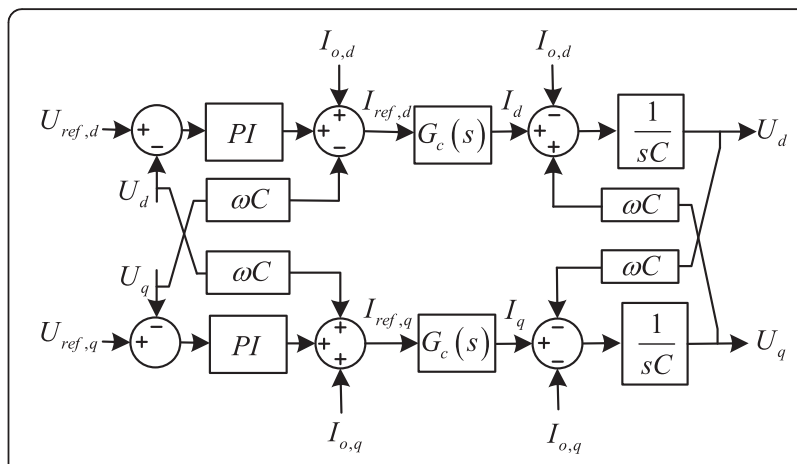

Fig. 4 Voltage control loop of GFM inverters in dq reference frame

power capacities, can deploy two different droop control

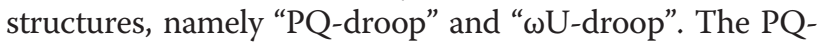
droop GS inverter adjusts its output power as a function of the variation of the microgrid's voltage and frequency. In this case, the inverter behaves like a power source and its control system is designed based on that of the GFD inverter, as shown in Fig. 5(a). On the contrary, the voltage and frequency at the $\mathrm{PC}$ of the $\omega \mathrm{U}$-droop GS inverter are adjusted according to the variations of its output power. The $\omega \mathrm{U}$-droop GS inverter behaves as a controlled voltage source and its control system is based on that of the GFM inverter, as shown in Fig. 5(b).

In Fig. 5, $\omega_{0}$ and $U_{0}$ represent the no-load frequency and no-load voltage, $k_{\mathrm{P}}$ and $k_{\mathrm{Q}}$ represent the active and reactive power droop coefficients, respectively. In steady state, the frequency of the microgrid is a global quantity, and the voltages at different points of the microgrid are almost identical. If " $\omega_{0}$ " and " $U_{0}$ " of each inverter are identical, then both the PQ-droop GS inverter and the $\omega U$ droop GS inverter can share load variations as follows:

$$
\begin{aligned}
& k_{p 1} \Delta P_{1}=k_{p 2} \Delta P_{2}=\ldots=k_{p n} \Delta P_{n} \\
& k_{Q 1} \Delta Q_{1}=k_{Q 2} \Delta Q_{2}=\ldots=k_{Q n} \Delta Q_{n}
\end{aligned}
$$

where $k_{\mathrm{Pi}}$ and $\Delta P_{\mathrm{i}}(\mathrm{i}=1,2, \ldots, \mathrm{n})$ represent the active power droop coefficient and output active power variation of the $i$ th GS inverter, respectively. $k_{\mathrm{Qi}}$ and ${ }^{\Delta} Q_{\mathrm{i}}$ represent the reactive power droop coefficient and output reactive power variation of the $i$ th GS inverter, respectively. Although both types of GS inverters shown in Fig. 5 have a good load-sharing performance, the PQdroop GS inverter cannot operate by itself. In contrast, the $\omega \mathrm{U}$-droop GS inverter is controlled as a voltage source, and thus can work independently regardless of the microgrid operation mode. The $\omega \mathrm{U}$-droop GS inverter has acquired extensive attentions for its excellent features though some problems still exist, including: 


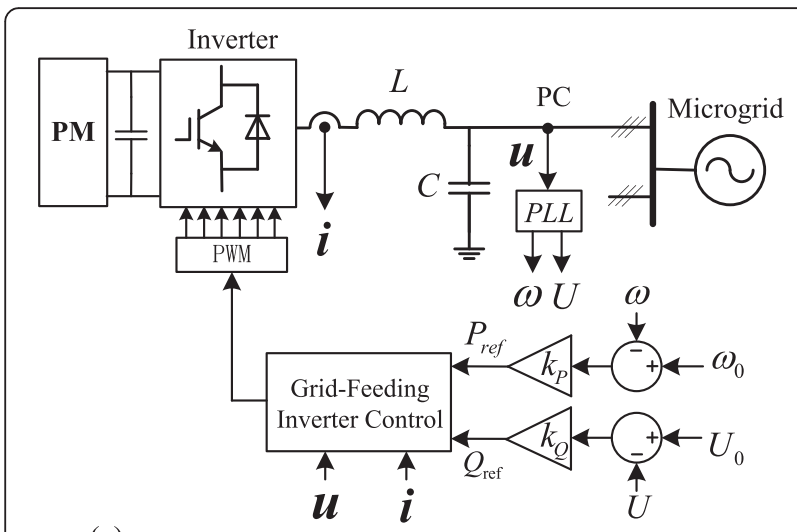

(a) Control block diagram of PQ-droop grid-supporting inverter

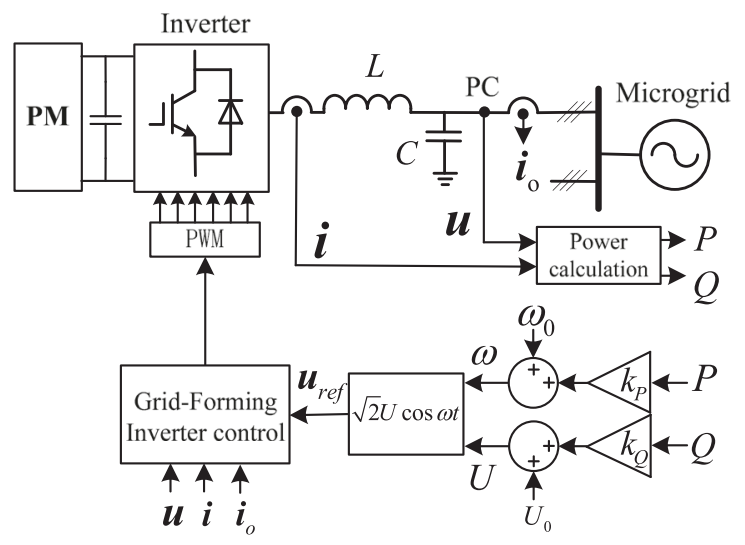

(b) Control block diagram of $\omega \mathrm{U}$-droop grid-supporting inverter

Fig. 5 Control block diagram of grid-supporting inverter. a Control block diagram of PQ-droop grid-supporting inverter. b Control block diagram of $\omega \mathrm{U}$-droop grid-supporting inverter

- the line impedance of a low-voltage microgrid has a large resistive component, thus $\mathrm{P}-\omega$ and $\mathrm{Q}-\mathrm{U}$ droop control is no longer suitable.

- the voltages at the PCs of each inverter are not completely equal, thus the GS inverters cannot share reactive power precisely.

Many researchers have proposed various improved methods to deal with the above problems and some typical schemes will be presented in the following sections.

\section{A. Decoupling transformation method}

As depicted in Fig. 6, the voltage at the PC of the $\omega \mathrm{U}$-droop $\mathrm{GS}$ inverter is denoted by $\mathrm{U} \angle \delta$, and the voltage at the microgrid bus is denoted by $\mathrm{E} \angle 0$. $\mathrm{Z}_{\mathrm{L}}$ is the line impedance between the inverter's filter capacitor and the microgrid bus with an impedance angle of $\theta$.

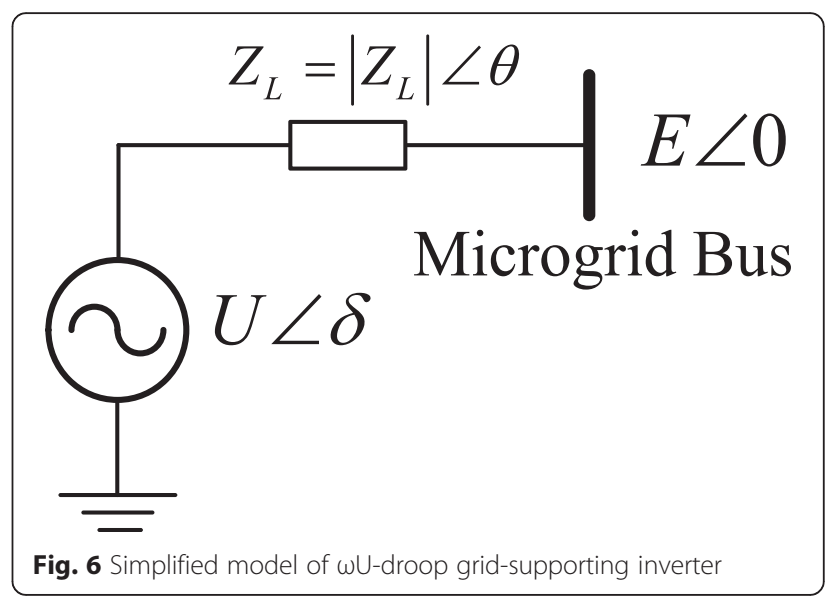

Due to the small power angle $\delta$, it is assumed that:

$$
\sin \delta=\delta, \cos \delta=1
$$

Thus, the output power of the GS inverter can be expressed as:

$$
\left\{\begin{array}{l}
P=\frac{E U \cos \theta-E^{2} \cos \theta+E U \delta \sin \theta}{Z_{L}} \\
Q=\frac{E U \sin \theta-E^{2} \sin \theta-E U \delta \cos \theta}{Z_{L}}
\end{array}\right.
$$

If both the resistive and reactive components of the line impedance cannot be ignored, the output active and reactive power of the inverter will be dependent on both $\delta$ and $U$. In this case, the $\mathrm{P}-\omega(\delta)$ and $\mathrm{Q}-\mathrm{U}$ decoupling relation will no longer valid. To solve this problem, the virtual power P', Q' and the transformer matrix $T_{\mathrm{PQ}}$ are introduced in $[12,13]$ :

$$
\left[\begin{array}{l}
P^{\prime} \\
Q^{\prime}
\end{array}\right]=T_{P Q}\left[\begin{array}{l}
P \\
Q
\end{array}\right]=\left[\begin{array}{cc}
\sin \theta & -\cos \theta \\
\cos \theta & \sin \theta
\end{array}\right]\left[\begin{array}{l}
P \\
Q
\end{array}\right]
$$

According to Eq. (11) and (12), it can be derived that:

$$
\left\{\begin{array}{l}
P^{\prime}=\frac{E U}{Z} \delta \\
Q^{\prime} \frac{E U-E^{2}}{Z}
\end{array}\right.
$$

The $\omega \mathrm{U}$-droop control based on the virtual power is given as:

$$
\left\{\begin{array}{l}
\omega=\omega_{0}-k_{P} P^{\prime} \\
U=U_{0}-k_{Q} Q^{\prime}
\end{array}\right.
$$

Similarly, transforming $\omega(\delta)$ and $U$ with the matrix $T_{\omega \mathrm{U}}$ [14] gives the virtual frequency (phase angle) and voltage as:

$$
\left[\begin{array}{l}
\omega^{\prime}\left(\delta^{\prime}\right) \\
U^{\prime}
\end{array}\right]=T_{\omega E}\left[\begin{array}{l}
\omega(\delta) \\
U
\end{array}\right]=\left[\begin{array}{cc}
\sin \theta & \cos \theta \\
-\cos \theta & \sin \theta
\end{array}\right]\left[\begin{array}{l}
\omega(\delta) \\
U
\end{array}\right]
$$

According to Eq. (11) and (15), it can be derived that: 


$$
\left\{\begin{array}{l}
P=\frac{E U \delta^{\prime}+\left(U-U^{2}-E^{2}\right) E \quad \cos \theta}{Z} \\
Q=\frac{E U U^{\prime}+\left(U-U^{2}-E^{2}\right) E \quad \sin \theta}{Z}
\end{array}\right.
$$

Since $E$ and $U$ are constant when the droop control process reaches steady-state, the output active and reactive power of the GS inverter will be regulated by the virtual frequency and voltage respectively. Thus, a novel $\omega \mathrm{U}$-droop can be established:

$$
\left\{\begin{array}{l}
\omega^{\prime}=\omega_{0}^{\prime}-k_{P} P \\
U^{\prime}=U_{0}^{\prime}-k_{Q} Q
\end{array}\right.
$$

In Eq. (17), $\omega_{0}$ ' and $U_{0}^{\prime}$ is the corresponding virtual noload frequency and voltage. The droop control block diagram of the GS inverters applying two types of decoupling transformation method is shown in Fig. 7.

It is worth noting that the first decoupling method is designed to share the virtual power rather than the real power. So there exists a complicated relation between the variations of each inverter's output power and their droop coefficients when the load in the microgrid changed. The second decoupling method avoids this problem considering that all inverters have the same $\omega^{\prime}$ and $U^{\prime}$, i.e. the $R / X$ of each line in the microgrid must be identical. In addition, the variables directly controlled by Eq. (17) are $\omega^{\prime}$ and $U^{\prime}$, and thus, it is necessary to carefully select the droop coefficients [14] to ensure that the real frequency and voltage are located in reasonable ranges.

B. Virtual impedance method

The coupling between the output active and reactive power of the conventional $\omega \mathrm{U}$-droop control can be mitigated by introducing virtual impedance [15], as illustrated in Fig. 8. The voltage at the inverter's $\mathrm{PC}$ is expressed as:

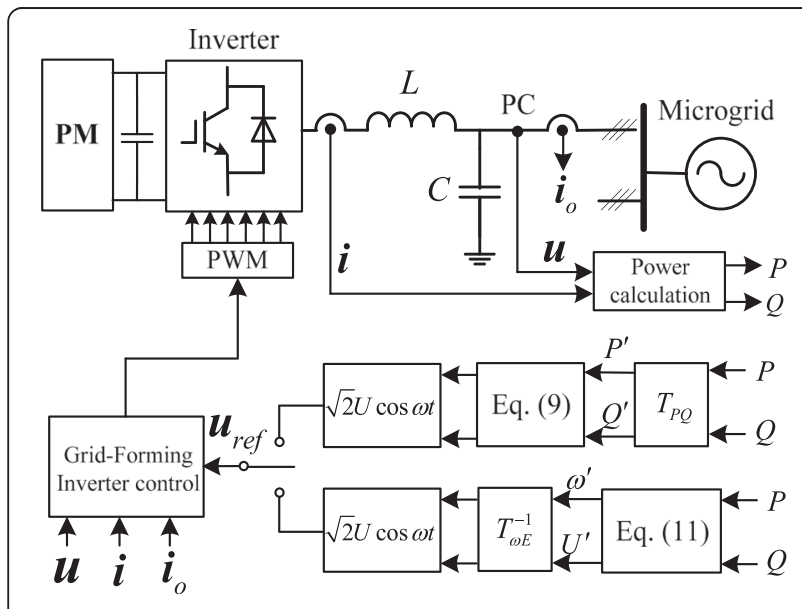

Fig. 7 Control block diagram of $\omega U$-droop Grid-supporting inverter applying decoupling transformation method

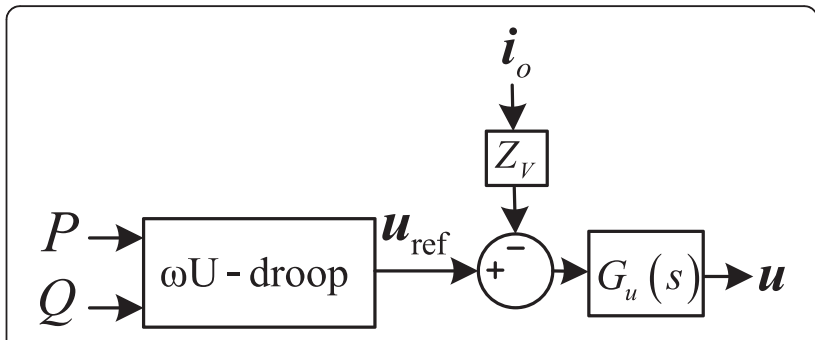

Fig. 8 Control structure of virtual impedance method

$$
U=G_{u}(s) U_{r e f}-G_{u}(s) Z_{V} I_{o}
$$

where $G_{u}(s)$ is the voltage closed-loop transfer function of the $\omega \mathrm{U}$-droop GS inverter, and $Z_{\mathrm{V}}$ is virtual impedance.

The total impedance between the equivalent voltage source of the inverter and the microgrid bus can be written as:

$$
Z=G_{u}(s) Z_{V}+Z_{L}
$$

where $Z_{\mathrm{L}}$ is the line impedance.

If the magnitude of the virtual impedance is much larger than the line impedance, the total impedance will be largely decided by the virtual impedance. However, the large total impedance may cause the microgrid voltage to reduce substantially. In [16], a novel method was proposed to solve this problem by introducing a negative resistive component into the virtual impedance. As the virtual negative resistor counteracts the line resistor, the total impedance can be designed to be mainly inductive and of small magnitude. According to Eq. (11), if the total impedance is mainly inductive [17], the GS inverter should adopt P- $\omega$ and Q-U droop control. However, if the total impedance is mainly resistive [18], P-U and Q- $\omega$ droop control should be applied.

\section{Reactive power sharing method based on communication}

To improve the reactive power sharing accuracy, a common method is to revise the GS inverters' droop control parameters, including no-load voltage and droop coefficient. The following analysis takes the inductive line $(\cos \theta \approx 0, \sin \theta \approx 1)$ as examples. According to Eq. (11), the relation between the output reactive power and the voltage of the GS inverter's $\mathrm{PC}$ is shown as:

$$
U=E+\frac{Z_{L}}{E} Q
$$

In the Q-U plane, the intersection of the operational curve described by Eq. (20) and the reactive power droop curve is the GS inverter's stable operating point [19]. 
As illustrated in Fig. 9, there are two inverters, namely $1 \#$ and 2\#, with the same droop coefficient. The total impedance between these two inverters' equivalent voltage sources and the microgrid bus are $Z_{1}$ and $Z_{2}$, respectively. If $Z_{1}$ is not equal to $Z_{2}$, the inverters' operating points will be different. Increasing inverters' droop coefficient leads to new operating points. The voltage of the microgrid bus moves from $E$ to $E$, and the inverters' output power changes move from $Q_{1}$ and $Q_{2}$ to $Q_{1}{ }^{\prime}$ and $Q_{2}{ }^{\prime}$, respectively It can be seen that the reactive power sharing accuracy is improved with the increase of the inverter's droop coefficient. Decreasing the GS inverter's no-load voltage can also increase reactive power sharing accuracy, as shown in Fig. 10. To adjust each inverter's droop curve parameters in a coordinated manner $[19,20]$, it is necessary to employ a centralized control system.

Different with the method of adjusting droop parameter, reference [21] proposed an improved control structure by introducing integral module, as shown in Fig. 11.

In Fig. 11, $U_{0}$ is the inverter no-load voltage; $E$ is the voltage of microgrid bus; $k_{\mathrm{Q}}$ is the reactive power droop coefficient; $K_{\mathrm{u}}$ is the integral gain. The transfer function of the inverter's output reactive power can be written as:

$$
Q(s)=\frac{K_{u}\left[U_{o}-E(s)\right] E(s)-s E^{2}(s)}{s Z_{L}+K_{u} k_{Q} E(s)}
$$

and its steady-state value can be calculated as:

$$
\begin{aligned}
\lim _{t \rightarrow \infty} Q(t) & =\lim _{s \rightarrow 0} s Q(s) \\
& =\lim _{s \rightarrow 0} \frac{\left(U_{0}-E\right) K_{u} E-s E^{2}}{s Z_{L}+K_{u} k_{Q} E}=\frac{U_{0}-E}{k_{Q}}
\end{aligned}
$$

In this method, the output reactive power of each GS inverter is independent to the line impedance $Z_{\mathrm{L}}$. By delivering the voltage information of the microgrid bus to each GS inverter, accurate reactive power sharing can be

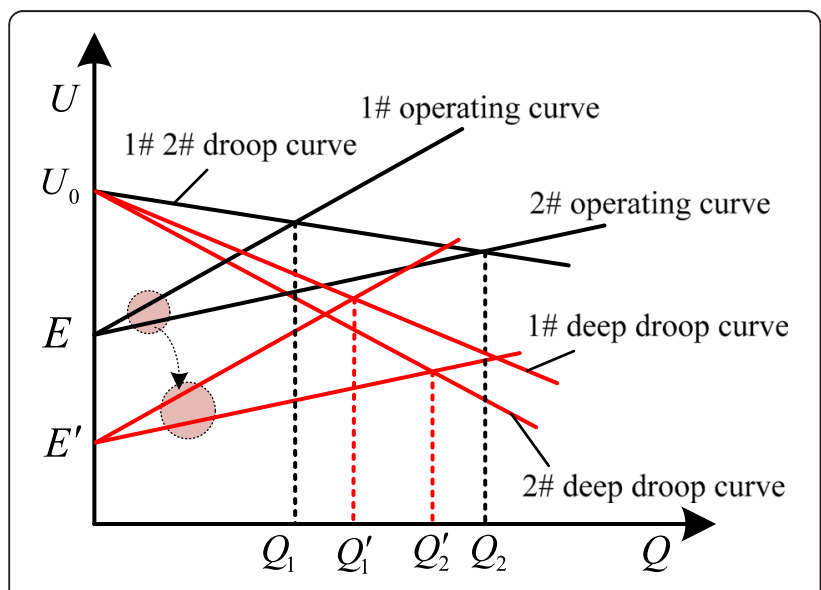

Fig. 9 Reactive power sharing with different droop coefficients

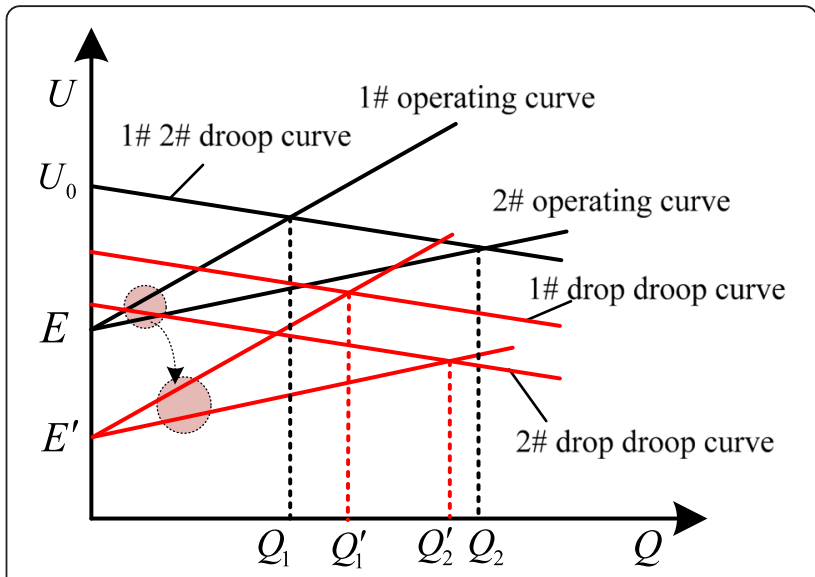

Fig. 10 Reactive power sharing with different no-load voltages

realized. This method doesn't require a central controller to participate, avoiding the usage of complicated algorithms. Besides, the additional parameter, $K_{\mathrm{u}}$, can be used to adjust the dynamic response of reactive power control.

\section{Results and Discussion}

As can be seen from the above sections, the GFD inverter behaves as constant power source and it participates neither in voltage regulation nor in load variations sharing. The GFM inverter behaves as constant voltage source and it is responsible not only for maintaining the microgrid's voltage and frequency, but also for keeping power balance. Load sharing among the GFM inverters is a function of the impedances between the inverters and microgrid bus. The PQ-droop and $\omega \mathrm{U}$-droop GS inverters can be regarded as the upgraded version of the GFD and GFM inverters, and they behave as controlled power source and controlled voltage source, respectively. When the microgrid operation conditions change, they can adaptively adjust the output power or voltage to achieve a more flexible load sharing. Currently the most promising control method is the $\omega \mathrm{U}$-droop control, because it can make the system autonomy and achieve seamless mode switching. When the microgrid is operated in islanded mode, any

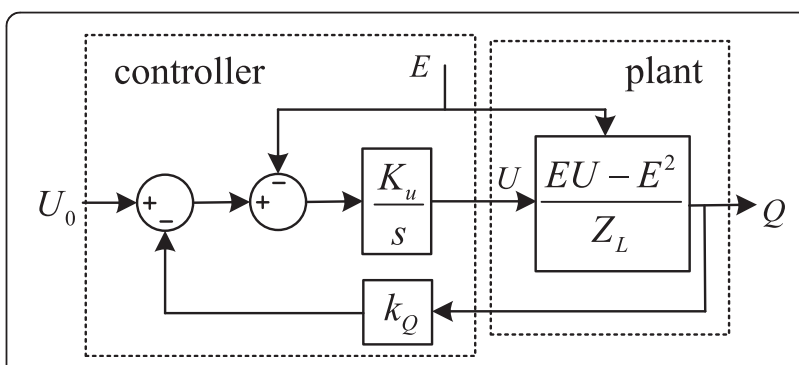

Fig. 11 Large-signal representation of the proposed reactive power control 
addition or reduction of a single $\omega \mathrm{U}$-droop GS inverter do not influence the configuration of the original system. When the microgrid operated in grid-connected mode, the $\omega \mathrm{U}$-droop GS inverter can output the specified power by modifying its no-load voltage and frequency. However, this autonomous control method is not widely applied among numerous experimental microgrids, because there still exist many practical problems, such as the dynamic response speed, the impact of control parameters on system stability, the capability to deal with unbalanced and non-linear loads, and control strategies under fault conditions. In addition, it can be seen from the above analysis that the performance of the $\omega \mathrm{U}$-droop GS inverter operating with no communication is inferior. In order to enhance the accuracy of reactive load sharing, it is worthwhile to study the design of the control algorithms with reduced communication requirements.

\section{Conclusions}

This paper illustrates the control principles of microsource inverters, including grid-feeding, grid-forming, and grid-supporting inverters. The PQ-droop and $\omega \mathrm{U}$-droop grid-supporting inverters can be regarded as the upgraded version of grid-feeding and grid-forming inverters with a more flexible load sharing capability. Since the conventional $\omega \mathrm{U}$-droop control exists some shortages, several improved methods of $\omega \mathrm{U}$-droop based grid-supporting inverters are presented. The comparison of various inverters is carried out and the valuable research points are also discussed.

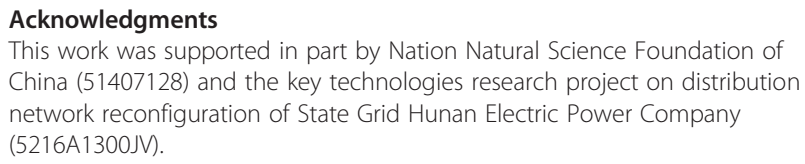

\section{Competing interests}

The authors declare that they have no competing interests.

\section{Authors' contributions}

WG and LM conceived and designed the study. WG wrote the paper. All authors read and approved the final manuscript.

\begin{abstract}
About the authors
W. M. Guo was born in 1989 in Hunan, China. He received his B.S. degrees in electrical engineering from Tongji University in 2011, where he is currently working towards a Ph.D. degree. His current research interests are microgrid protection and control.

L. H. Mu was born in 1963 in Jiangsu, China. He is currently a full professor in the Department of Electrical Engineering, Tongji University, Shanghai, China. His current research interests include protective relaying of power system, microgrid and power quality.
\end{abstract}

Received: 12 May 2016 Accepted: 16 May 2016

Published online: 27 June 2016

\section{References}

1. Kroposki, B., Pink, C., Deblasio, R., et al. (2010). Benefits of power electronic interfaces for distributed energy systems. IEEE Transactions on EnergyConversion, 25, 901-908.
2. Walling, R. A., Saint, R., Dugan, R. C., et al. (2008). Summary of distributed resources impact on power delivery systems. IEEE Transactions on PowerDelivery, 23, 1636-1643.

3. Lopes, J. A. P., Moreira, C. L., \& Madureira, A. G. (2006). Defining control strategies for MicroGrids islanded operation. IEEE Transactions on Power Systems, 21, 916-924.

4. Nikkhajoei, H., \& Lasseter, R. H. (2009). Distributed generation interface to the CERTS microgrid. IEEE Transactions onPower Delivery, 24, 1598-1608.

5. Olivares, D. E., Mehrizi-Sani, A., Etemadi, A. H., et al. (2014). Trends in microgrid control. IEEE Transactions onSmart Grid, 5, 1905-1919.

6. Ali, B., \& Ali, D. (2012). Hierarchical structure of microgrids control system. IEEE Transactions onSmart Grid, 3, 1963-1976.

7. Fangzheng, P., \& Jih-Sheng, L. (1996). Generalized instantaneous reactive power theory for three-phase power systems. IEEE Transactions on Instrumentation and Measurement, 45, 293-297.

8. Camacho, A., Castilla, M., Miret, J., et al. (2015). Active and reactive power strategies with peak current limitation for distributed generation inverters during unbalanced grid faults. IEEE Transactions on Industrial Electronics, 62, 1515-1525.

9. Miret, J., Camacho, A., Castilla, M., et al. (2013). Control scheme with voltage support capability for distributed generation inverters under voltage sags. IEEE Transactions onPower Electronics, 28, 5252-5262.

10. Zmood, D. N., Holmes, D. G., \& Bode, G. H. (2001). Frequency-domain analysis of three-phase linear current regulators. IEEE Transactions onIndustry Applications, 37, 601-610.

11. Rocabert, J., Luna, A., Blaabjerg, F., et al. (2012). Control of power converters in AC microgrids. IEEE Transactions onPower Electronics, 27, 4734-4749.

12. De Brabandere, K., Bolsens, B., Van den Keybus, J., et al. (2007). A voltage and frequency droop control method for parallel inverters. IEEE Transactions onPower Electronics, 22, 1107-1115.

13. Zhou, X., Rong, F., Lu, Z., et al. (2012). A coordinate rotational transformation based virtual power $\mathrm{V} / \mathrm{f}$ droop control method for low voltage microgrid. Automation of Electric Power Systems, 36, 47-51.

14. Li, Y., \& Li, Y. W. (2011). Power management of inverter interfaced autonomous microgrid based on virtual frequency-voltage frame. IEEE Transactions onSmart Grid, 2, 30-40.

15. Guerrero, J. M., Vicuña, D., García, L., et al. (2005). Output impedance design of parallel-connected UPS inverters with wireless load-sharing control. IEEE Transactions onIndustrial Electronics, 52, 1126-1135.

16. Zhang, P., Shi, J., Ronggui, L. I., et al. (2014). A control strategy of virtual negative impedance for inverters in Low-voltage microgrid. Proceedings of the CSEE, 34, 1844-1852.

17. Chen, Y., Luo, A., Long, J., et al. (2013). Circulating current analysis and robust droop multiple loop control method for parallel inverters using resistive output impedance. Proceedings of the CSEE, 33, 18-29.

18. Matas, J., Castilla, M., et al. (2010). Virtual impedance loop for droopcontrolled single-phase parallel inverters using a second-order generalintegrator scheme. IEEE Transactions onPower Electronics, 25, 2993-3002.

19. Han, H., Liu, Y., Sun, Y., et al. (2014). An improved control strategy for reactive power sharing in microgrids. Proceedings of the CSEE, 34, 2639-2648.

20. Jin, P., Xin, A. I. \& Wang, Y. (2012). Reactive power control strategy of microgird using potential function method. Proceedings of the CSEE, 32, 44-51.

21. Sao, C. K., \& Lehn, P. W. (2005). Autonomous load sharing of voltage source converters. IEEE Transactions on Power Delivery, 20, 1009-1016.

\section{Submit your manuscript to a SpringerOpen ${ }^{\circ}$ journal and benefit from:}

- Convenient online submission

- Rigorous peer review

- Immediate publication on acceptance

- Open access: articles freely available online

- High visibility within the field

- Retaining the copyright to your article

Submit your next manuscript at springeropen.com 